Conclusions: Pts with CDAI $\leq 35-36$ at $\mathrm{BL}$ achieved sustained LDA more frequently and more rapidly than pts in the higher disease category at BL. In pts with higher disease activity at $\mathrm{BL}$ a more robust response was observed with bari $4 \mathrm{mg}$ treatment.

References:

[1] Dougados M et al. Ann Rheum Dis 2017; 76(1):88-95.

[2] Taylor P et al. Arthritis Rheumatol 2015; 67(Suppl 10):1-4046

Disclosure of Interest: J. Curtis Grant/research support from: AbbVie, Amgen, BMS, Corrona, Eli Lilly and Company, Janssen, Myriad, Pfizer, Roche/Genentech, UCB, Consultant for: AbbVie, Amgen, BMS, Corrona, Eli Lilly and Company, Janssen, Myriad, Pfizer, Roche/Genentech, UCB, A. Kavanaugh Consultant for: Eli Lilly and Company, D. van der Heijde Consultant for: AbbVie, Amgen, Astellas, Astra-Zeneca, BMS, Boeringer Ingelheim, Celgene, Daiichi Sankyo, Eli Lilly and Company, Galapagos, Gilead, Janssen, Merck, Novartis, Pfizer, Regeneron, Roche, Sanofi-Aventis, UCB, Employee of: Director of Imaging Rheumatology bv, D. Muram Employee of: Eli Lilly and Company, J. Alam Employee of: Eli Lilly and Company, J. Smolen Grant/research support from: Abbvie, Janssen, Eli Lilly and Company, MSD, Pfizer, Roche, Consultant for: Abbvie, Amgen, AstraZeneca, Astro, BMS, Celgene, Celltrion, Chugai, Gilead, Glaxo, ILTOO, Janssen, Eli Lilly and Company, Medimmune, MSD, Novartis-Sandoz, Pfizer, Roche, Samsung, Sanofi-Aventis, UCB, Speakers bureau: Abbvie, Amgen, Astra-Zeneca, Astro, BMS, Celgene, Celltrion, Chugai, Gilead, Glaxo, ILTOO, Janssen, Eli Lilly and Company, Medimmune, MSD, Novartis-Sandoz, Pfizer, Roche, Samsung, Sanofi-Aventis, UCB

DOI: 10.1136/annrheumdis-2017-eular.1340

\section{AB0236 ASSOCIATION OF LYVE-1 PROTEIN IN EXOSOME WITH DISEASE ACTIVITY AS A NEW CANDIDATE BIOMARKER FOR RHEUMATOID ARTHRITIS}

J. Yoo ${ }^{1}$, S.K. Lee ${ }^{2}$, M. Lim ${ }^{1}$, D. Sheen ${ }^{1}$, E.-H. Choi ${ }^{2}$, S.A. Kim ${ }^{1} .{ }^{1}$ School of Medicine; ${ }^{2}$ Eulji Medi-Bio Research Institute, Eulji University, Daejeon, Korea, Republic Of

Background: Exosomes, membrane-bound vesicles of $40-100 \mathrm{~nm}$ in diameter, have protein and lipid composition that depends on the cell origin, the state of activation, infection and/or transformation of the parent cells. Those proteins and lipid have a role in mediating inflammatory and autoimmune disease as well. Discovery of inflammatory marker to evaluate appropriate response of treatment could give effective timing to adjust treatment for rheumatoid arthritis patients.

Objectives: The aim of the study was to identify protein candidates in exosome being related with other inflammatory parameters.

Methods: The study population consisted of 60 RA patients, in which there were 30 patients of clinical remission (CR) group with DAS28-ESR $<2.6$ and 30 patients of non-clinical remission (non-CR) group with DAS28-ESR $>2.6$. By exosome preparation with ExoQuick ${ }^{\mathrm{TM}}$ kit and protein identification with tandem mass tags labeling/mass spectrometry between the groups, potent protein markers were selected. Level of the proteins was measured by ELISA.

Results: We identified 6 proteins by proteomics approach. Amyloid A (AA) and lymphatic vessel endothelial hyaluronic acid receptor-1 (LYVE-1) was identified with different levels in exosome between $\mathrm{CR}$ group and non-CR group. AA levels of both serum and exosome were higher in non-CR group than CR group ( $p$ value $=0.001$ ). Significant positive correlations were found between exosome AA level and CRP as well as between serum AA level and CRP $(\rho=0.614, p$ value $=0.001$ and $\rho=0.624, p$ value $=0.001$ ). Though $L Y V E-1$ level of serum was not different between non-CR group and CR group, LYVE-1 level of exosome was lower in non-CR group than CR group ( $p$ value $=0.01$ ). We found positive correlations between serum/exosome of LYVE-1 and CRP in only non-CR group (serum $\rho=0.376$, $p$ value $=0.04$; exosome $\rho=0.545$, $p$ value $=0.002$ ).

Conclusions: We suggest that LYVE-1 in exosome can be used as an additional marker of disease activity in RA patients and this study provides the evidence about the role of exosome for RA as the carrier of useful marker.

References:

[1] Mathivanan S, Ji H, Simpson RJ. Exosomes: extracellular organelles important in intercellular communication. J Proteomics. 2010 Sep;73(10):1907-20.

[2] Shen C, Sun X-G, Liu N, et al. Increased serum amyloid A and its association with autoantibodies, acute phase reactants and disease activity in patients with rheumatoid arthritis. Mol Med Rep. 2015;11(2):1528-34.

[3] Nunomiya K, Shibata Y, Abe S, et al. Relationship between serum level of lymphatic vessel endothelial hyaluronan receptor-1 and prognosis in patients with lung cancer. J Cancer. 2014;5(3):242-7.

Disclosure of Interest: None declared

DOI: 10.1136/annrheumdis-2017-eular.1194

\section{AB0237 PREVALENCE AND CLINICAL CHARACTERISTICS OF MALIGNANCY IN SEROPOSITIVE RHEUMATOID ARTHRITIS PATIENTS}

J. Park, C. Lee. Nhis Ilsan Hospital, Goyang, Korea, Republic Of

Background: Patients with rheumatoid arthritis (RA) are at an increased risk of malignancies compared with the general population.

Objectives: The aim of this study was to evaluate the prevalence and risk factors of malignancy in National Health Insurance Service Ilsan hospital patients with seropositive RA.

Methods: We found patients with seropositive RA who fulfilled the American College of Rheumatology criteria and American College of Rheumatology criteria/European League Against Rheumatism criteria, from May 2008 to September 2015. Occurrence of malignancy was originally collected by electronic medical record reports and diagnostic code. We consecutively enrolled patients with newly diagnosed malignancy. Control group was selected as five times the number of patients randomized.

Results: Total 12 malignancies in 647 patients were newly identified during the retrospective observation period of 2051 person-years. Malignancy types were 3 lung cancers, 2 colon cancers, gastric cancer, breast cancer, thyroid cancer, cervix cancer, cholangiocarcinoma, lymphoma and parotid gland cancer. In multivariate logistic regression, the variables with independent predictive value were older age (age: odds ratio $=1.11,95 \% \mathrm{Cl}=1.01-1.22, \mathrm{p}$-value $=0.02$ ), rheumatoid factor (RF) negativity (RF positivity: odds ratio $=0.06 .95 \% \mathrm{Cl}=0.01-1.27$, $p$-value 0.07 ) In cox regression, the variables with independent predictive value were older age (age: hazard ratio $=1.12,95 \% \mathrm{Cl}=1.01-1.24, \mathrm{p}$-value $=0.02$ ), negative $\mathrm{RF}$ (RF positivity: hazard ratio $=0.12 .95 \% \mathrm{Cl}=0.02-0.78$, p-value 0.02 ), lower anti-cyclic citrullinated peptide (CCP) antibody titer (anti-CCP antibody titer: hazard ratio $=0.98 .95 \% \mathrm{Cl}=0.96-0.99$, p-value 0.03 ) and positive antinuclear-antibody (ANA) (ANA positivity: hazard ratio $=14.97,95 \% \mathrm{Cl}=0.87-255.05$, p-value 0.06 ).

Table 1. Associations between variables and malignancy event in subjects: longitudinal data

\begin{tabular}{lcccccccc}
\hline Variables & \multicolumn{3}{c}{ Univariable } & & \multicolumn{3}{c}{ Multivariable } \\
\cline { 2 - 3 } & Hazard ratio & $95 \% \mathrm{Cl}$ & $\mathrm{p}$-value & & Hazard ratio & $95 \% \mathrm{Cl}$ & $\mathrm{p}$-value \\
\hline Etiology & & & & & & & & \\
$\quad$ Age & 1.14 & $1.05-1.24$ & $<0.01$ & & 1.12 & $1.01-1.24$ & 0.02 \\
$\quad$ Gender & 3.71 & $0.47-29.08$ & 0.21 & & & & \\
Laboratory results & & & & & & & \\
$\quad$ RF positivity & 0.33 & $0.09-1.13$ & 0.07 & & 0.12 & $0.02-0.78$ & 0.02 \\
$\quad$ Anti-CCP Ab titer & 0.99 & $0.98-1.00$ & 0.10 & & 0.98 & $0.96-0.99$ & 0.03 \\
$\quad$ ANA positivity & 5.56 & $0.69-44.64$ & 0.10 & & 14.97 & $0.87-255.05$ & 0.06 \\
\hline
\end{tabular}

Conclusions: Age, RF positivity, anti-CCP antibody titer, ANA positivity may be associated with malignancy risk in seropositive rheumatoid arthritis. So, continued vigilance and regular cancer screening are recommended for case of older age, RF negativity, lower anti-CCP antibody titer and ANA positivity.

Disclosure of Interest: None declared

DOI: 10.1136/annrheumdis-2017-eular.1587

\section{AB0238 THE INFLUENCE OF FATIGUE IN THE DEFINITION OF REMISSION IN RHEUMATOID ARTHRITIS PATIENTS TREATED WITH TOCILIZUMAB}

$\underline{\text { J. Caetano }}^{1}$, S. Oliveira ${ }^{1}$, J. Delgado Alves ${ }^{1,2} .{ }^{1}$ Systemic Autoimmune Diseases Unit, Department of Medicine IV, Fernando Fonseca Hospital, Amadora;

${ }^{2}$ CEDOC, NOVA Medical School, Lisbon, Portugal

Background: Achieving disease remission or low disease activity is the therapeutic goal in rheumatoid arthritis' (RA) treatment. Disease activity is defined through established criteria most of them requiring the evaluation of patient global assessment (PGA). PGA is considered a limiting factor for achieving remission definition, as it can be influenced by many factors not RA-related, namely fatigue which is commonly reported in RA and has been correlated with increased levels of interleukin-6 (IL-6).

Objectives: To evaluate the relation between PGA and fatigue, and whether fatigue influences disease remission definition in RA patients treated with tocilizumab (TCZ), an anti-IL-6 receptor monoclonal antibody.

Methods: We prospectively recruited 18 consecutive patients with RA (ACR/EULAR 2010 criteria), on TCZ treatment ( $>3$ months), from a single referral centre. Disease activity was evaluated by disease activity score for 28-joints (DAS28), and the ACR/EULAR Boolean-based criteria for remission were calculated. Visual Analog Scale for Fatigue (VASF) and Multidimensional Assessment of Fatigue scale (MAF) were used to measure fatigue.

Results: $89 \%$ of the patients were female and mean age was $55.5 \pm 13.8$ years (yrs). Mean disease duration was $8.8 \pm 6.8 \mathrm{yrs}$ and mean duration of TCZ treatment was $2.3 \pm 1.3 y r s(50 \% 1$ st line). Mean PGA score was $3.3 \pm 2.0$ (0-best health) and mean DAS28 C-reactive protein (CRP) was 2.27. According to DAS28-CRP 44\% of the patients were in remission, $22 \%$ had low disease activity and $33 \%$ had moderate activity. 3 patients (17\%) fullfield the ACR/EULAR Boolean criteria for remission. Considering all the composits of the Boolean criteria, PGA was the only reason for not achieving remission in 10 patients $(56 \%)$. The mean fatigue scores were: VASF 6.6 \pm 2.3 (0-best health), Global Fatigue Index (GFI), calculated through MAF scale, $24.3 \pm 14.9$ (1-best health). Amongst the 18 patients, PGA correlated with higher fatigue scores on VASF $(r=0.50, p=0.00951)$ and on GFI $(r=0.49, p=0.037)$. In the group of patients not fulfilling Boolean remission, a similar correlation between PGA and higher fatigues scores was found (VASF: $r=0.54, p=0.036$; GFI: $r=0.79, p=0.00041)$. In the sub-group of patients in which $\mathrm{PGA}$ was the only factor for not achieving Boolean remission, there was a significant correlation between PGA and fatigue scores ( $G F I: r=0.79, p=0.009$ ), that was not present in the other patients (GFI: $r=0.24 ; p=0.49$ ).

Conclusions: We found a positive correlation between higher PGA and fatigue 